\title{
Effect of Papaverine on the Flow of Left Internal Thoracic (Mammary) Artery for Coronary Artery Bypass Grafting
}

\author{
Musfireh Siddiqeh* \\ Assistant professor of cardiac surgery, Rawalpindi Institute of Cardiology, Pakistan \\ Received: April 20, 2018; Published: May 01, 2018 \\ *Corresponding author: Musfireh Siddiqeh, Assistant professor of cardiac surgery, Rawalpindi Institute of Cardiology, Pakistan
}

Abstract

Objective: To determine the effect of papaverine in the blood flow of internal mammary artery in patientsundergoing coronary artery bypass grafting surgery.

Study Design: Quasi-experimental study. 2015.

Place \& Duration: Cardiac surgery departments of Punjab Institute of Cardiology in Lahore, Pakistan from 1stMarch 2015 to 1st November

Methods: This descriptive case series study enrolled 50 consecutive patients who had undergone elective coronary artery bypass grafting with cardiopulmonary bypass (CPB) with use of papaverine in internal mammary artery, aged range 36-78 years were selected from cardiac surgery departments of Punjab Institute of Cardiology, Lahore, Pakistan from 1stMarch 2015 to 30th November 2015. All patients were assessed pre-operatively and per-operatively blood flow of LIMA at baseline (before papaverine injection) for 15 seconds and after 30 minutes of intra-arterial papavarine injection is measured.

Results: Out of 50 patients of which $10(20 \%)$ were female while $40(80 \%)$ were male. The mean age of the patients was $54 \pm 11.79$ years and the average number of graft was $2.6 \pm 0.72$. Results showed significant improvement in mean blood flow of LIMA $(12.81 \pm 8.07 \mathrm{ml}$ and $61.87 \pm 8.45 \mathrm{ml}$ per 15 seconds and one minute respectively at baseline while $27.23 \pm 11.54 \mathrm{ml}$ and $107.53 \pm 44.35 \mathrm{ml}$ per 15 seconds and one minute respectively after 30 minute of papaverine injection)as p-value $\leq 0.05$.

Conclusion: Papaverineis safe and effective vasodilator for increasingmean blood flowof LIMA/LITA for coronary artery bypass grafting surgery.

Abbreviations: CPB: Cardiopulmonary Bypass; CAPG: Coronary Artery Bypass Grafting; LITA or LIMA: Left Internal Thoracic(Mammary) Artery; PDE III-I: Phosphodiesterase III inhibitor; LAD: Left Anterior Descending Artery; SD: Standard Deviation; SPSS: Statistical Package for Social Sciences; PAM: Mean Arterial Pressure

\section{Introduction}

Coronary artery bypass grafting $(\mathrm{CABG})$ is commonly performed procedure in cardiac surgery. However, patients being referred for surgical revascularization now are more complex and have higher risks than in previous decades [1-4]. As increased risk of suffering from ischemic complications coincident with graft failure. The choice of conduits for CABG plays an important role in mortality and morbidity especially with the increasingly complex patient population. The ideal conduit for bypass the LAD, most centers use the left internal thoracic (mammary) artery (LITA or LIMA). The
LITA arise from their respective subclavian artery. LITA/LIMA in coronary artery bypass grafting associated with approximately $90 \%$ long-term graft patency, improved flow rate and lower mortality and morbidity rate.Spasms can occur during CABG surgery, both during harvesting and after the grafting causes early myocardial ischemia and often reduces early graft flow, which could cause perioperative morbidity and even death in high-risk patients [5]. that may be minimized by the local action of vasodilatory agents i.e. (carbon dioxide, papaverine, Phosphodiesterase III inhibitor 
(PDE III-I), nitroprusside solution, glyceriltrinitrate, diltiazem and normal saline etc [6-9].

Utilization of vasodilators applied to the LITA in an attempt to minimize the spasms [10-12] and promote a greater blood flow during the perioperative period.The most famous one is the solution of Papaverine $[13,14]$ at ambient temperature $\left(20^{\circ} \mathrm{C}\right.$ to $22^{\circ} \mathrm{C}$ ) as a topical vasodilator. However, the pharmacologic actions of papaverine generally have been assessed at $37^{\circ} \mathrm{C}$, which initially was proposed to be injected intraluminally. Despite many other drugs available for spasm prevention, papaverine remains in use in the majority of cardiac centers. The papaverine injections are the most widely accepted approach. The use of papaverine remains controversial as it has no clear improved flow rate over other vasodilatory agents and importantly, significant possible underappreciated side effects, despite the widespread use of papaverine in the region to treat the condition.Therefore, this study aims to evaluate the effects of papaverine on the blood flow of the left internal thoracic (mammary) artery (LITA or LIMA).

\section{Material and Methods}

This quasi-experimental study was conducted at cardiac surgery departments of Punjab Institute of Cardiology in Lahore, Pakistan from 1stMarch 2015 to 1st November 2015. Patients of either gender who had undergone elective coronary artery bypass grafting with cardiopulmonary bypass (CPB), aged range 3678 years were included in the study. Patients with osteoporotic sternum, emphysematous lungs and the cases were LIMA was not harvested were excluded from the study. Total 50 patients fulfilling the inclusion criteria were enrolled in the study through consecutive sampling.In all patients the left internal thoracic or mammary artery (LITA or LIMA) was grafted to the left anterior descending artery (LAD). After examining the patient and relevant investigations, an informed consent was obtained from each patient. All operation was performed by same surgeon. Demographic history was noted for each patient i.e. gender, age, BMI (calculated by weight/squared height ratio). Routine CABG was done under mild hypothermia $\left(28^{\circ} \mathrm{C}\right)$ with ante-grade blood cardioplegia. No topical epicardial cooling is used at our institution.Left internal thoracic or mammary artery (LITA or LIMA) was dissected by classic pedicled technique. A small incision was made into the endothoracic fascia medial to the ITA/IMA pedicle and adjacent to the superior border of a costal cartilage. Dissection of the pedicle was completed by continuing the incision in the endothoracic fascia through the length of the pedicle, and the pedicle was gently separated from the chest wall by blunt dissection.

The length of the LITA/LIMA was considered from its origin to its end at the bifurcation or trifurcation; Haemo-clips were applied on all lateral branches and at the end of the pedicle. After LIMA harvesting Heparin, 300units/kg, was given an aortic and double stage venous cannulation done. Then cardiopulmonary bypass established.The LIMA flow was measured at mean arterial pressure (PAM) of $60 \mathrm{mmHg}$ for 15 seconds. Flow per minute was then calculated.Papaverine $2 \mathrm{ml}(5 \mathrm{mg})$ in $30 \mathrm{~mL}$ of normal saline at a temperature of $37^{\circ} \mathrm{C}$ was injected in an identical manner intraiarterially throughout the vessel using branula with syrange
$(10 \mathrm{ml})$ with care to avoid vascular wall infiltration but after the LIMA/LITA was harvested and occluded with hemoclips. The mammary artery was transected 2 to $3 \mathrm{~cm}$ proximal to its bifurcation. The LIMA flow was measured after 30 minutes at mean arterial pressure (PAM) of $60 \mathrm{mmHg}$ for 15 seconds. Flow per minute was then calculated. All the information was collected on a specially designed performa.

\section{Statistical Analysis}

Data had been analyzed using SPSS (Statistical Package for Social Sciences) Version 20.0 for Window. Mean and standard deviation (SD) were used to describe quantitative variables. Frequencies along with percentages were calculated for qualitative variables. To study the significance of effect of papaverine (treatment), pre and post average flow rates were compared using paired t test. A p-value $<0.05$ was considered as significant.

\section{Results}

Total 50 patients were studied of which $40(80 \%)$ were males. Average age of the patients was 54 years $(S=11.79)$ with minimum age of 35 years and maximum age of 68 years. Average number of graft was $2.6(\mathrm{SD}=0.72$ ). The mean pre-operative $\mathrm{EF}$ was 46.76 $(\mathrm{SD}=10.20)$. Most common comorbid conditions were hypertension (42\%) and diabetes mellitus (42\%) followed by smoking (28\%) while hyperlipidemia (4\%) and family history of IHD (14\%) were less common among patients harvested LIMA/LITA. Post-operative before papaverine injection (baseline) average blood flow was $12.81 \pm 8.07 \mathrm{ml}$ per 15 seconds and $61.87 \pm 11.45 \mathrm{ml}$ per minute. After 30 minutes of papaverine injection average blood flow was $27.23 \pm 8.54 \mathrm{ml}$ per 15 seconds and $107.53 \pm 14.35$ per minute. After giving papaverine injection, average blood flow was significantly increased per 15 seconds $(\mathrm{p}<0.001)$ and per one minute $(\mathrm{p}<0.001)$ (Figures $1 \& 2$ ) and (Table 1).

Table 1: Comparison of blood flow of patients before and after papaverine $(\mathrm{n}=50)$.

\begin{tabular}{|c|c|c|c|}
\hline $\begin{array}{c}\text { Blood flow } \\
\text { (ml) }\end{array}$ & $\begin{array}{c}\text { Beforepapaverine } \\
\text { administration }\end{array}$ & $\begin{array}{c}\text { After } \\
\text { papaverine } \\
\text { administration }\end{array}$ & p-value \\
\hline Per 15 Sec & $12.81 \pm 8.07$ & $27.23 \pm 8.54$ & $<0.001$ \\
\hline Per 1 minute & $61.87 \pm 11.45$ & $107.53 \pm 14.35$ & $<0.001$ \\
\hline
\end{tabular}

Values are described as mean \pm SD

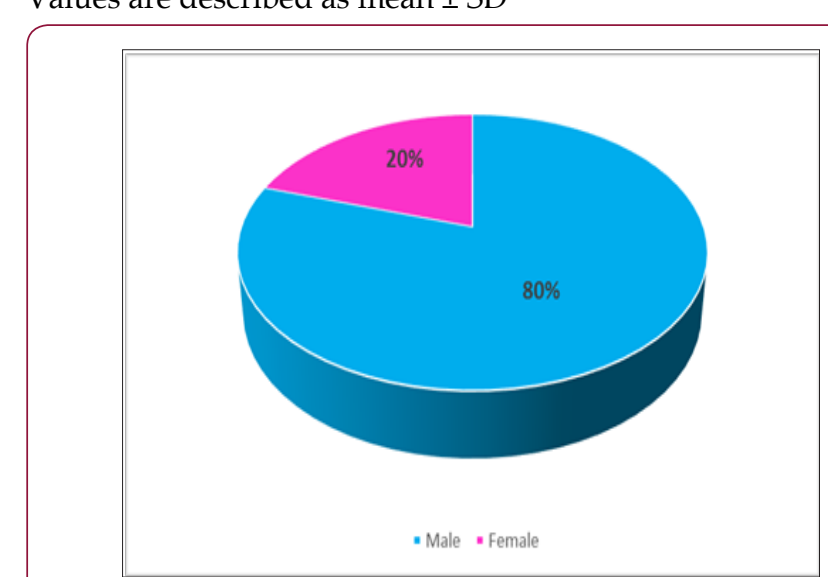

Figure 1: Gender distribution of patients $(n=50)$. 


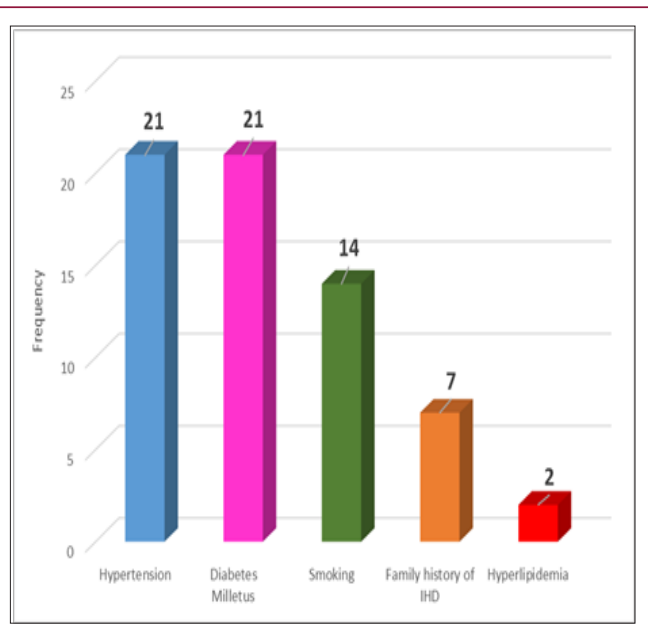

Figure 2: Description of comorbid conditions among patients $(n=50)$.

\section{Discussion}

Present study indicates that male patients are more who undergo CABG and harvested LIMA/LITA as compared to female ( $80 \%$ vs. $20 \%$ ). Ozkara C et al scrutinized that patients with LIMA/ LITA harvested were more likely to be men (79\% vs. $21 \%)$ Vilandt J et al. [15] found that LIMA harvested was more in male than female (88\% vs. 12\%) [12] The present study provides evidence that LIMA/LITA graft for CABG during surgery patients were of age $54 \pm 11.79$ years. Koramaz I et al and Ozkara $C$ et al demonstrated that LIMA/LITA graft for CABG was more commonly found in older patients as $61.4 \pm 12.6$ years and $66 \pm 4.4$ years respectively $[15,16]$ Takeuchi $\mathrm{K}$ et al examined that patient harvested with LIMA/LITA scheduled for CABG was found to be older as mean $69 \pm 9.6$ years [6] may be different co-morbid conditions in these studies, present study showed dissimilar results.Papaverine is a well-known internationally accepted arterial vasodilator used .We chose to utilize it in the LIMA/LITA harvested patients, pre and post mean differences of flow rate was analyzed, there is a significant evidence that the flow rates of the LIMA/LITA increased significantly with time after vasodilator response to papaverine as $12.81 \pm 8.07 \mathrm{ml}$ per 15 seconds and $61.87 \pm 11.45 \mathrm{ml}$ per minute before papavarine injection (at baseline) while $27.23 \pm 8.54 \mathrm{ml}$ per 15 seconds and $107.53 \pm 14.35 \mathrm{ml}$ per minute after $30 \mathrm{~min}$ of papavarine injection (Table 1).

Our results are comparable with the study by Ozkara $\mathrm{C}$ examined that free flow of the internal thoracic artery increased significantly with time after vasodilator response to papaverine as (pre $49.8 \pm$ 11.6 and post $78.8 \pm 13.6 \mathrm{ml}$ per minute; $p$-value 0.02 ) [15] Further study by Girard et al reported evidence for safe prevention of spasm is for papaverine given topically and peri-arterially as (before $86.2 \pm$ 12.0 after $139.7 \pm 11.0 \mathrm{ml} / \mathrm{min}$ ) after $30 \mathrm{~min}$ of papavarine injection [17] Another study by Koramaz I showed that vasodilatory agent, papaverine, can increase the flow rates of the grafts as (baseline $40.2 \pm 13.0 \mathrm{ml}$ after $53.4 \pm 10.7 \mathrm{ml} / \mathrm{min}$ ) after $30 \mathrm{~min}$ of papavarine injection [16] Takeuchi K et al examined that papaverine treatment showed no significant increase in blood flow as (baseline 37.2 \pm $17.0 \mathrm{ml}$ to after $40.2 \pm 19.1 \mathrm{ml} / \mathrm{min}$ ) [6].

\section{Conclusion}

Papaverine delivery to the left internal mammary artery after harvested treats spasm effectively, increased blood flow significantly / invariably will double their flow after 30 minutes of papavarine injection.

\section{References}

1. Farkouh ME, Domanski M, Fuster V (2013) Revascularization strategies in patients with diabetes. N Engl J Med 368: 1453-1456.

2. Weintraub WS, Grau-Sepulveda MV, Weiss JM, Sean M O'Brien, Eric D Peterson, et al. (2012) Comparative effectiveness of revascularization strategies. N Engl J Med 366: 1467-1476.

3. Kappetein AP, Head SJ, Morice MC (2013) Treatment of complex coronary artery disease in patients with diabetes: 5-year results comparing outcomes of bypass surgery and percutaneous coronary intervention in the SYNTAX trial. Eur J Cardiothorac Surg 43(5): 1006-1013.

4. Kolh P, Jochen Cremer, Volkmar Falk, Gerasimos Filippatos, Christian Hamm, et al. (2010) Task Force on Myocardial Revascularization of the European Society of Cardiology (ESC) and the European Association for Cardio-Thoracic Surgery (EACTS), European Association for Percutaneous Cardiovascular Interventions (EAPCI), Guidelines on myocardial revascularization. Eur J Cardiothorac Surg 38: S1-S52.

5. Sarabu MR, McClung JA, Fass A, Reed GE (1987) Early postoperative spasm in left internal mammary artery bypass grafts. Ann Thorac Surg 44(2): 199-200.

6. Takeuchi K, Sakamoto S, Nagayoshi Y, Nishizawa H, Matsubara J (2004) Reactivity of the human internal thoracic artery to vasodilators in coronary artery bypass grafting. Eur J Cardiothorac Surg 26(5): 956-959.

7. Hendrick BB (1973) Blood flow in the internal mammary artery. Am Heart J 86(4): 570-571.

8. Hillier C, Watt PA, Spyt T], Thurston H (1992) Contraction and relaxation of human internal mammary artery after intraluminal administration of papaverine. Ann Thorac Surg 53(6): 1033-1037.

9. Zabeeda D, Medalion B, Jackobshvilli S, Ezra S, SchachnerA, et al. (2001)Comparison of systemic vasodilators: effects on flow in internal mammary and radial arteries. Ann Thorac Surg 71(1): 138-141.

10. Mills NL, Bringase WL (1989) Preparation of the internal mammary artery graft: which is the best method? J Thorac Cardiovasc Surg 98(1): 73-79.

11. Cooper GJ, Wilkinson GA, Angelini GD (1992) Overcoming perioperative spasm of the internal mammary artery:which is the best vasodilator? J Thorac Cardiovasc Surg 104(2): 465-468.

12. Vilandt J, Kjaergard H, Aggestrup S, Andreasen JJ, Olesen A (1999) Intraluminal papaverine with $\mathrm{pH} 3$ doubles blood flow in the internal mammary artery. Scand Cardiovasc J 33(6): 330-332.

13. Mills NL, Ochsner JL(1975) Preparations of internal mammary arteries for coronary bypass with intraluminal papaverine. J Cardiovasc Surg (Torino) 16: 632-633.

14. Green GE (1971) Rate of blood flow from the internal mammary artery. Surgery 70(6): 809-813.

15. Ozkara C, Dogan OF, Furat C (2012) Effect of topical vasodilator on internal thoracic artery blood flow. A placebo-controlled clinical study. World Journal of Cardiovascular Diseases 2: 204-207.

16. Koramaz I, Pulathan Z, Usta S, Karahan SC, Alver A, et al. (2006) Cardioprotective effect of cold-blood cardioplegia enriched with $\mathrm{N}$-acetylcysteine during coronary artery bypass grafting 81(2): 613-618.

17. Girard DS, Sutton JP, Williams TH, Crumbley AJ, Zellner JL, et al. (2004) Papaverine delivery to the internal mammary artery pedicle effectively treats spasm. Ann Thorac Surg 78(4): 1295-1298. 


\section{(c) (i) This work is licensed under Creative} Submission Link: https://biomedres.us/submit-manuscript.php

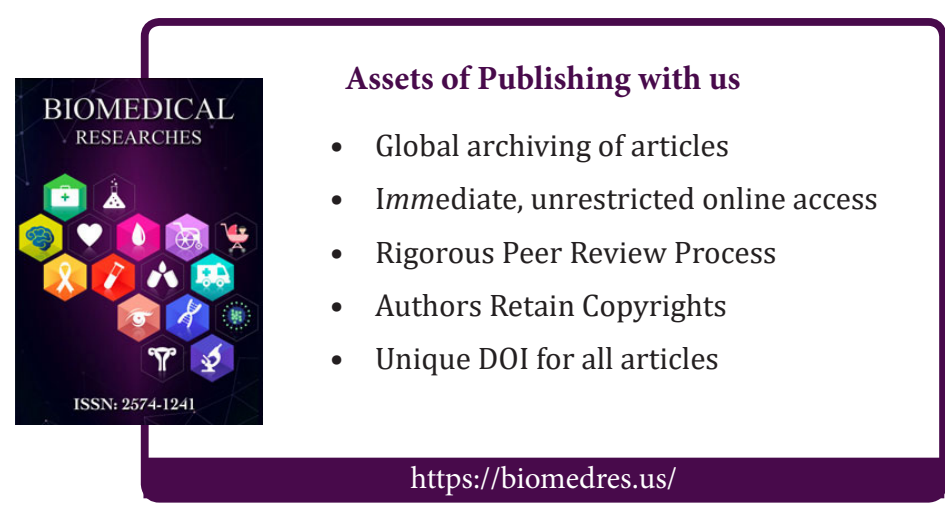

